\title{
OBLITERATION OF EMPYEMA TRACT WITH DEEPITHELIALIZED UNIPEDICLE TRANSVERSE RECTUS ABDOMINIS MYOCUTANEOUS FLAP
}

Joseph M. Serletti, MD

Richard H. Feins, MD

Alexis J. Carras, MD

Joseph E. Losee, MD

David W. Johnstone, MD

H. Raul Herrera, MD

George L. Hicks, Jr., MD
Four patients with chronic empyema after pneumonectomy have undergone successful obliteration of the empyema tract with a deepithelialized transverse rectus abdominis myocutaneous flap. The deepithelialized skin island has provided sufficient bulk for tract obliteration. Rotation of the skin island into the long axis of the rectus muscle has added considerable length to this flap, allowing it to reach the apex of the thoracic cavity. A recurrent loculation developed 4 months after the obliteration procedure in one patient. This was successfully treated with open pleural drainage and a second Clagett procedure. Over a mean follow-up period of 35 months, all four patients are free of further infectious sequelae. Chest roentgenograms have confirmed eradication of the tracts in all four patients. ( $J$ Thorac Cardiovasc Surg 1996;112:631-6)
$E_{\mathrm{p}}^{\mathrm{m}}$ mpyema occurs in $2 \%$ to $16 \%$ of patients after -pneumonectomy and can be associated with bronchopleural fistula. ${ }^{1}$ The majority of postoperative empyemas occur within the first 4 weeks after pneumonectomy, but they may occur any time after the operation. The development of empyema has serious consequences for these patients, including multiple reoperations. In one large series, the average number of procedures performed in patients with postpneumonectomy empyema was five. ${ }^{1}$ Current initial surgical management of the postpneumonectomy empyema includes tube thoracostomy and open pleural drainage. ${ }^{2-4}$ A permanent thoracostomy might prevent recurrent infection and sepsis but it necessitates lifelong wound care. ${ }^{5}$

Closure of the thoracostomy can be performed to avoid the problems of a permanent chest wound. A variety of techniques have been described for thoracostomy closure. ${ }^{6-8}$ The most commonly used technique today was described by Clagett and $\mathrm{Geraci}^{8}$ in 1963. In this procedure, a clean empyema tract is first obtained through open pleural drainage.

From the Department of Surgery and the Divisions of Plastic Surgery and Cardiothoracic Surgery, University of Rochester, Rochester, N.Y.

Received for publication Dec. 4, 1995; revisions requested Feb. 5, 1996; revisions received Feb. 27, 1996; accepted for publication March 1, 1996.

Address for reprints: Joseph M. Serletti, MD, PO Box 661, Strong Memorial Hospital, 601 Elmwood Ave., Rochester, NY 14642.

Copyright (C) 1996 by Mosby-Year Book, Inc.

$0022-5223 / 96 \$ 5.00+0 \quad \mathbf{1 2 / 1 / 7 3 2 3 6}$
The thorax is then filled with antibiotic solution, and a watertight seal is created during thoracostomy closure. Recurrent empyema is an unfortunate complication of the Clagett procedure, occurring in $12 \%$ to $80 \%$ of treated patients. ${ }^{1,4}$ In addition, many patients may undergo multiple unsuccessful Clagett procedures, after which a chronic empyema tract remains. Failure to control the septic focus with these techniques has been a recurrent problem and has often been attributed to residual pleural dead space. ${ }^{1}$ In order to decrease the rate of recurrence, complete soft tissue obliteration of the empyema cavity has been advocated.

Multiple local muscle flaps have been used to provide successful obliteration. ${ }^{4,9}$ Local tissues most frequently used for obliteration are the serratus anterior and the latissimus dorsi muscles. These muscles, however, have often been divided in these patients, limiting their usefulness. In these instances other tissues, such as the pectoralis major and the omentum, have been used. ${ }^{1,4,7}$ Free tissue transfer has been used in a limited number of patients as well. ${ }^{10}$ The rectus abdominis muscle has not been used frequently ${ }^{1,4,7,9}$ and the use of the TRAM flap has been criticized because of limited length and bulk. ${ }^{11}$ Hallock ${ }^{9}$ reported a single case of closure of postpneumonectomy empyema with a TRAM flap and felt the TRAM flap should be limited to use in the lower thoracic cavity only. We present case reports of four patients who underwent successful obliteration of chronic empyema tracts with a modification of the TRAM flap that allowed transposition to the apex of the chest: the deepithelialized 


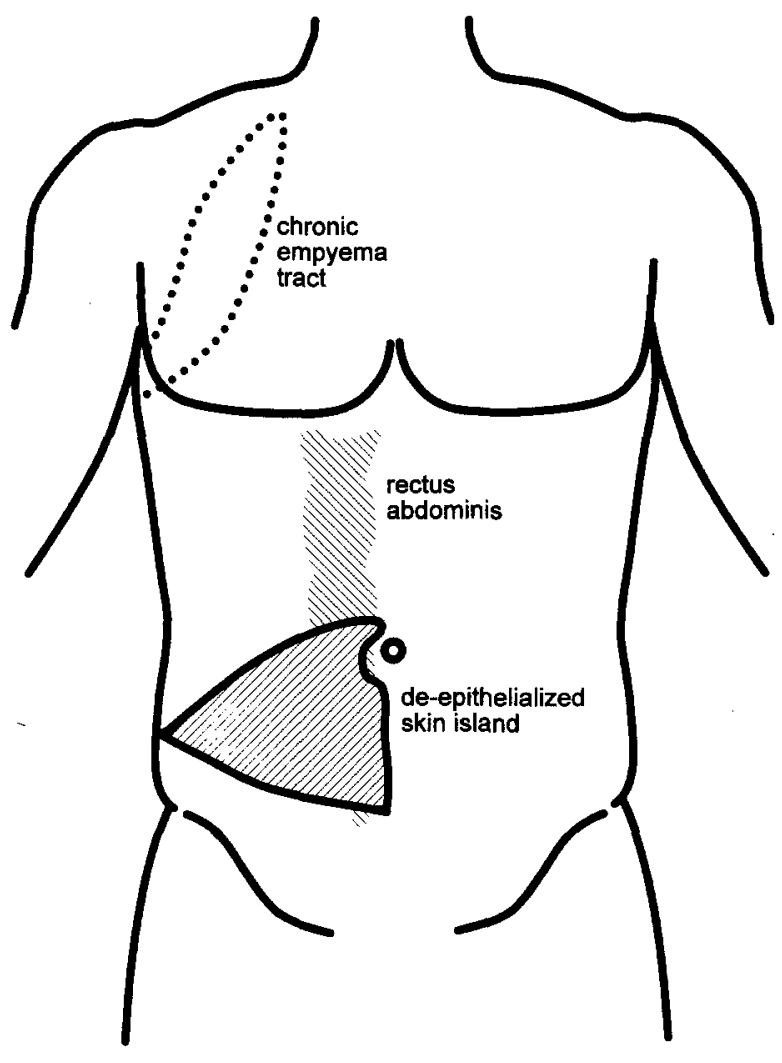

Fig. 1

unipedicle TRAM flap with rotation into the long axis of the flap.

\section{Patients and methods}

Over the past 5 years, four patients had extensive empyema tracts after pneumonectomy. There were two men and two women with a mean age of 68 years (Table I). The tracts extended from the thoracostomy site to the apex of the thorax. Local chest wall muscle in these patients was inadequate because of prior thoracotomies. These patients underwent empyema tact obliteration and closure with a deepithelialized unipedicle TRAM flap as described herein.

With the patient in the standing position, the typical transverse skin island of the TRAM flap was outlined. After induction of anesthesia, the patient was initially placed in the supine position. The rectus abdominis muscle ipsilateral to the empyema tract was elevated. The ipsilateral half of this skin island was then immediately deepithelialized (Fig. 1). This allowed maximum tension on the outlined skin island for easier deepithelialization. The upper abdominal skin flap was elevated to the xiphoid and above each costal margin. A subcutaneous tunnel was made between the upper abdominal dissection and the opening of the empyema tract for passage of the flap to the chest defect. The contralateral skin island was then elevated off the anterior rectus sheath and discarded as in abdominoplasty. This allowed for routine closure of the TRAM donor site.

The medial and lateral perforators to the deepithelialized skin island were harvested with the overlying anterior rectus sheath and rectus abdominis muscle. The full length of the rectus muscle was elevated from the pubis to above the costal margin. All lateral intercostal perforators to the rectus muscle were divided, including the most superior perforators beneath the costal margin. For added mobility, the superior epigastric vessels were dissected under loupe magnification, dividing small branches just below the costal margin.

So that the added length of the skin island and its rotation could be used, the island was rotated 90 degrees inferiorly into the long axis of the rectus muscle (Fig. 2). This rotation did not result in vascular compromise of the skin island. With the lateral edge of the deepithelialized skin island as the flap's leading edge, the flap was passed from the abdominal site to the chest defect through the previously developed subcutaneous tunnel. The rotation of the skin island supplied the additional length to reach the apex of the thorax through its rotation and the volume of the flap allowed for complete dead space obliteration (Fig. 3).

The TRAM donor site was closed in the standard manner. The deepithelialized skin island was temporarily sutured to the opening of the empyema tract. After abdominal closure, the patient was turned to the decubitus position. This permitted better access to the empyema tract for improved débridement. Further rib resection was performed to allow passage of the flap into the empyema cavity. Adequate local skin was elevated to completely cover the deepithelialized flap.

\section{Case reports}

CASE 1. A 69-year-old man underwent right pneumonectomy for bronchiectasis in 1939. In 1962, the right pleural cavity became infected with Salmonella, necessitating tube thoracostomy. A rib resection was also performed for osteomyelitis. Over the next 28 years, the empyema tract was successfully managed with tube thoracostomy, tract irrigations, and dressing changes. In 1990, a previously undrained loculation was found, which necessitated further rib resection and a Clagett procedure was attempted, which was unsuccessful. After this procedure, a large, clean, welldrained empyema tract remained (Fig. 4).

CASE 2. Tuberculosis was diagnosed in a 58-year-old woman in 1963. She was hospitalized in a sanitorium for 1 year and then underwent a right upper lobectomy to control the disease. She was admitted for recurrent tuberculosis in 1971. After this, the patient had a complicated course of recurrent pulmonary infections, bronchiectasis, hemoptysis, and productive cough. In 1990, a right pneumonectomy was performed for a large aspergilloma of the middle lobe, followed by amphotericin B therapy. In 1991, an empyema of the right thorax developed, necessitating posterior rib resection and open thoracostomy. A clean empyema tract remained with extension to the apex of the thorax after adequate local wound care. 


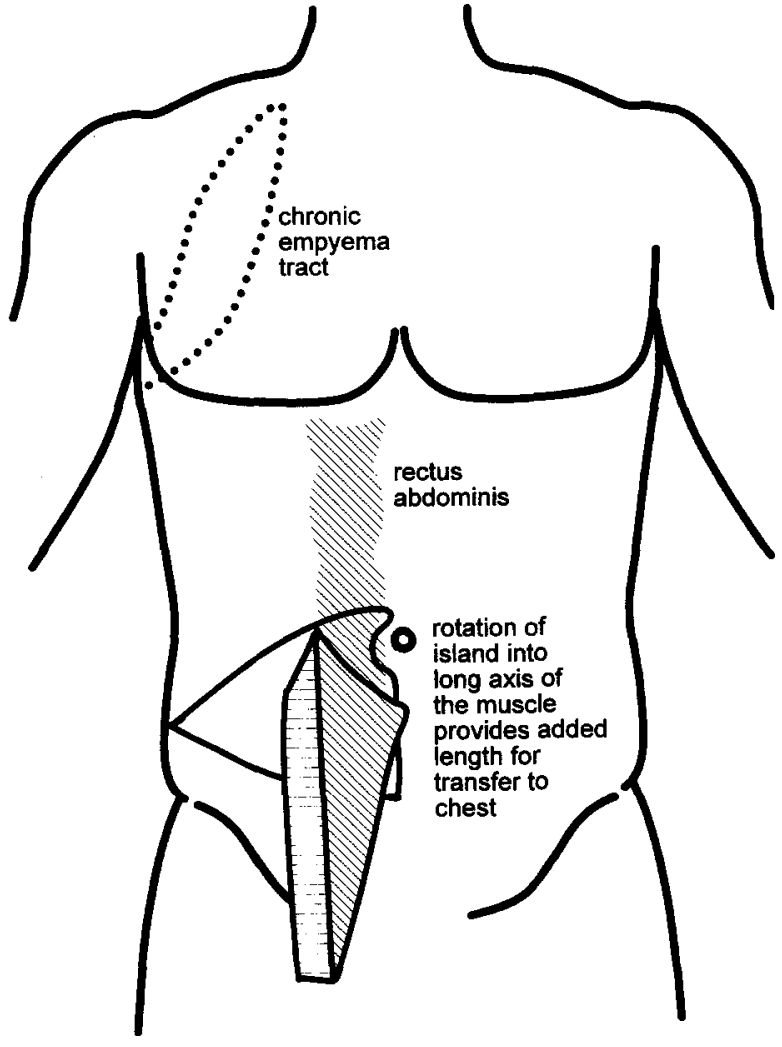

Fig. 2

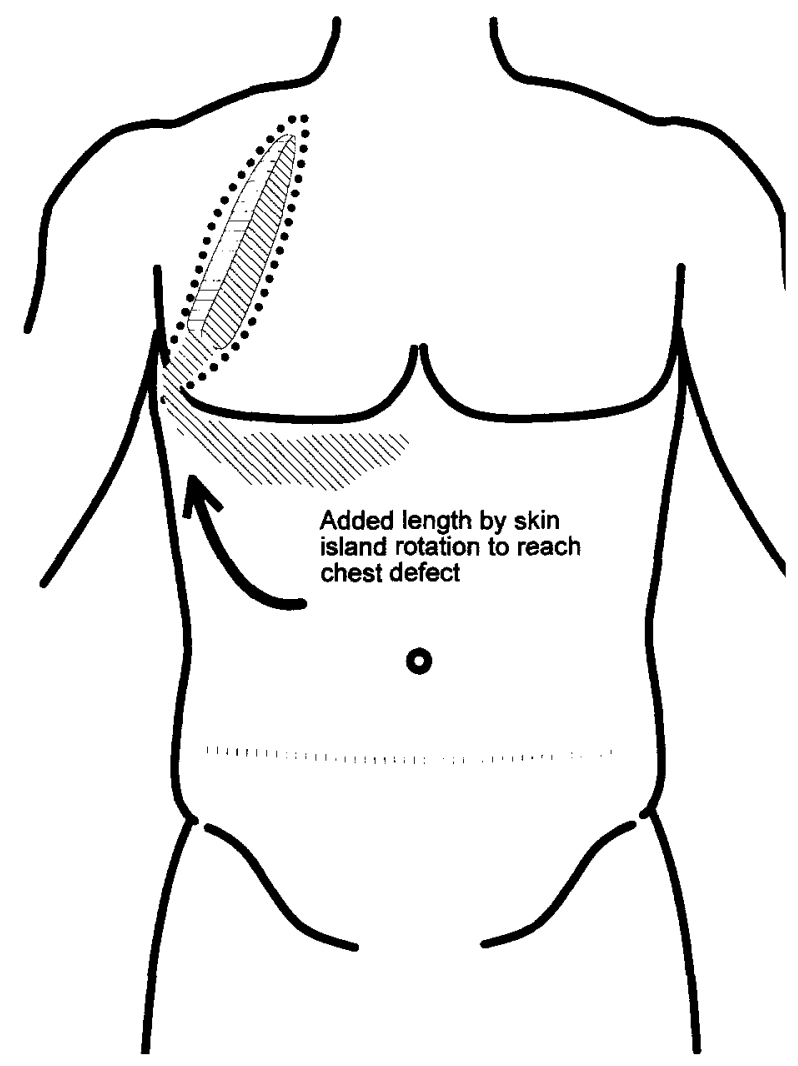

Fig. 3

Table I. Summary of patients treated with deepithelialized unipedicle TRAM flap

\begin{tabular}{|c|c|c|c|c|c|}
\hline $\begin{array}{c}\text { Patient } \\
\text { No. } \\
\text { (age, sex) }\end{array}$ & Diagnosis & $\begin{array}{l}\text { Time to } \\
\text { empyema }\end{array}$ & $\begin{array}{c}\text { Time from } \\
\text { empyema } \\
\text { to flap }\end{array}$ & $\begin{array}{l}\text { Follow-up } \\
\text { time }\end{array}$ & Outcome \\
\hline $1(72, M)$ & $\begin{array}{l}\text { Poorly differentiated non-small- } \\
\text { cell carcinoma }\end{array}$ & $1 \mathrm{mo}$ & 3 mo & $21 \mathrm{mo}$ & Good \\
\hline $2(71, M)$ & Bronchiectasis & $23 \mathrm{yr}$ & $28 \mathrm{yr}$ & $55 \mathrm{mo}$ & Good \\
\hline $3(60, F)$ & $\mathrm{TB}$ /aspergillosis & $1 \mathrm{yr}$ & $6 \mathrm{mo}$ & $55 \mathrm{mo}$ & Good \\
\hline $4(70, F)$ & $\begin{array}{l}\text { Poorly differentiated squamous } \\
\text { cell carcinoma }\end{array}$ & $6 \mathrm{mo}$ & $30 \mathrm{mo}$ & $10 \mathrm{mo}$ & $\begin{array}{l}\text { Good, second } \\
\text { Clagett }\end{array}$ \\
\hline
\end{tabular}

CASE 3. A 72-year-old man underwent left pneumonectomy for poorly differentiated non-small-cell lung carcinoma in 1993. At the time of the operation, an abscess was noted in the affected lung. Within 1 month, the patient had a left empyema that was colonized with Haemophilus influenzae and Klebsiella pneumoniae. He underwent an Eloesser procedure 1 month after the pneumonectomy. After 2 months of dressing changes after the Eloesser procedure, a clean tract remained.

CASE 4. A 70-year-old woman underwent right pneumonectomy in 1991 for poorly differentiated squamous cell carcinoma of the right lung. Six months later, a right empyema developed. After $2^{1 / 2}$ years of dressing changes, she underwent closure of the tract with the deepithelialized
TRAM flap. Several weeks after TRAM flap obliteration, fever and chest wound drainage developed. A recurrent infection was diagnosed and this was treated with a second open pleural drainage followed by a period of dressing changes. The tract that remained was much smaller than the initial empyema tract treated with the TRAM flap. A successful Clagett procedure was performed on this more limited tract. In addition, an incarcerated anterior abdominal hernia developed, necessitating small bowel resection. She recovered fully after this procedure.

Patients were observed for wound healing at the donor and recipient sites and for any sign of recurrent infection. Results have been recorded by direct observation and serial chest roentgenograms. 

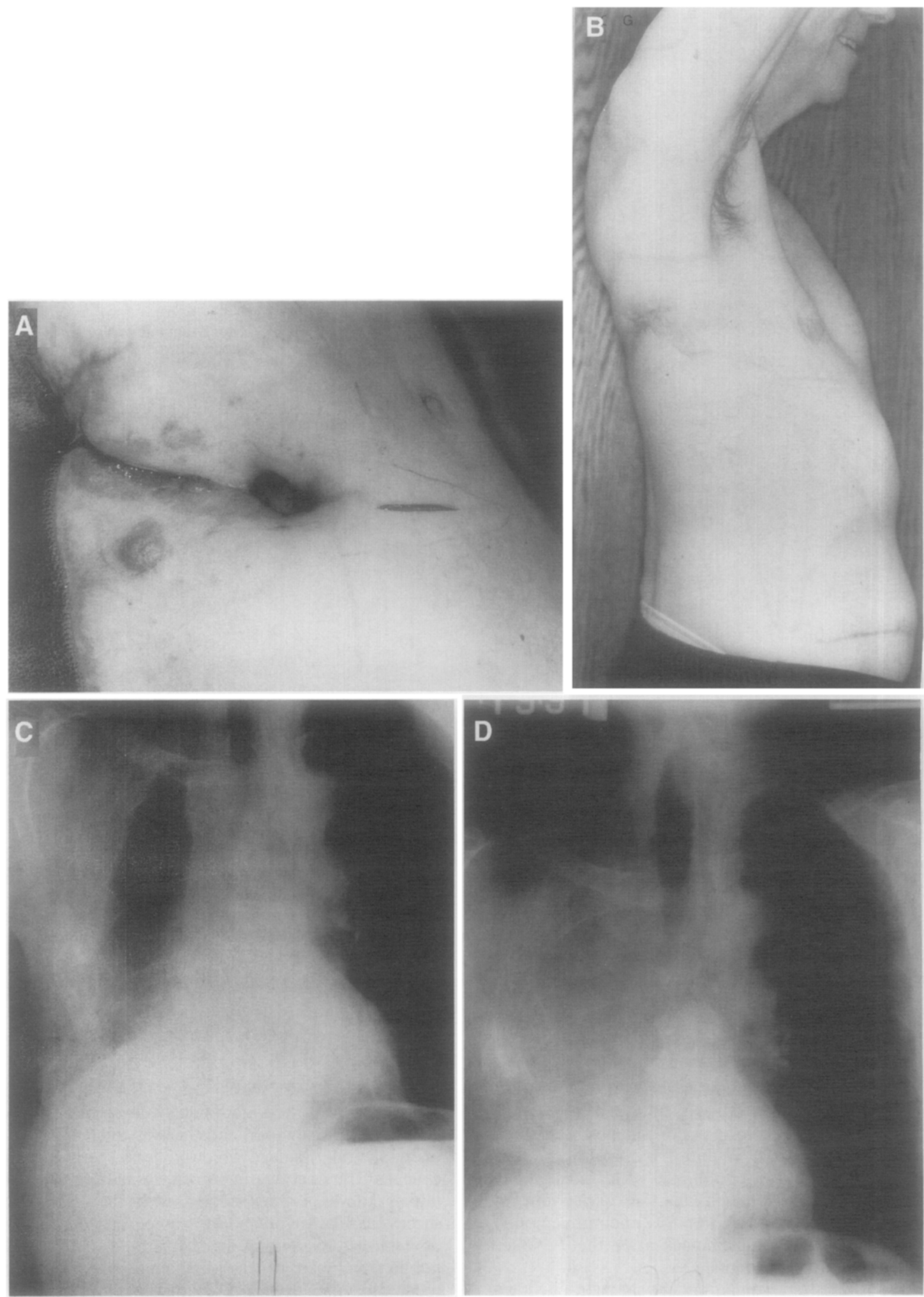

Fig. 4. A, Preoperative view of right lateral chest wall with open thoracostomy site. B, Postoperative view of lateral chest wall with healed thoracostomy site. C, Preoperative chest radiograph showing empyema tract in right lung field. D, Postoperative chest radiograph showing obliterated empyema tract. 


\section{Results}

After a clean wound had been established through adequate drainage and local care, these four patients underwent complete obliteration of their extensive empyema tracts. No perioperative complications developed. Chest roentgenograms from the immediate postoperative period showed complete obliteration of the previous tracts. Mean follow-up was 35 months. Serial chest roentgenograms over this follow-up period have demonstrated continued obliteration of the tracts in all four patients. One patient (patient 4) had a recurrent loculation after the obliteration procedure and was treated with a second Clagett procedure. This patient has since been free of infectious sequelae and the chest has remained closed for 10 months. The chest walls of the other three patients have remained healed, and the patients have been free of recurrent infection. Abdominal donor sites have healed without significant functional deficits in all four patients. An incarcerated hernia developed in one patient (patient 4) and necessitated a small bowel resection. This patient recovered from this event completely and has had no further problems at the abdominal donor site.

Patient satisfaction has been high, with all patients commenting that the relief from dressing changes was the most positive effect of the operation.

\section{Discussion}

The goal of optimum treatment of postpneumonectomy empyema tracts is permanent closure without late infectious sequelae. Other methods of surgical treatment, such as tube thoracostomy, might be successful in eliminating long-term infectious complications, but they are accompanied by lifelong dressing changes for the patient. ${ }^{5}$ Aside from the patient's dissatisfaction with this result, maintaining an open wound also places added nutritional demands on the patient and adds the potential for local neoplastic transformation at the wound site. Techniques for thoracostomy closure such as the Clagett procedure have been successful, but they are associated with a significant recurrence rate..$^{1,4}$ However, the low morbidity of this technique makes it a valid choice for initial management. For the recurrent empyema after an unsuccessful Clagett procedure or for persistence of a tract, strong consideration should be given to obliteration with wellvascularized soft tissue. ${ }^{4,9}$ Patients must be healthy enough to tolerate this procedure and should have a prognosis that justifies further reconstruction. These patients frequently have extensive smoking histories and decreased pulmonary reserve. They must be able to tolerate the intrathoracic portion of this procedure. In addition, recovery from TRAM flap operations involves maintaining flexion at the waist for several days. This posture could cause significant problems with pulmonary toilet resulting in atelectasis and pneumonia.

Multiple features of muscle flaps and myocutaneous flaps contribute to their ability to treat chronic wounds. The volume of tissue provided by these flaps for the complete obliteration of dead space is probably their most useful feature. Local muscle flaps, such as the serratus anterior and the latissimus dorsi, have been successful in the long-term resolution of bronchopleural fistula and chronic empyema tracts through dead space obliteration. However, patients with chronic empyema frequently have had several thoracic procedures. Pneumonectomy, followed by thoracotomy, chest wall resection, thoracoplasty, or a combination of these procedures, has usually rendered the use of local muscles impossible. ${ }^{11}$ The TRAM flap has previously been used for closure of the fenestra after the Clagett procedure ${ }^{6}$ and for closure of empyema tracts in the lower one third of the thoracic cavity. ${ }^{4,9}$ This study has demonstrated successful obliteration of chronic empyema tracts with the deepithelialized unipedicle TRAM flap in patients with inadequate local muscle for reconstruction. This procedure is advantageous for several reasons. There is no need to use the remaining local flaps such as the pectoralis, which are limited in their volume and length and may affect upper extremity function. A laparotomy for omental flaps is avoided. Free tissue transfer with the added difficulty of finding appropriate recipient vessels is also avoided.

The deepithelialized unipedicle TRAM flap described in this report provided adequate length and volume for complete empyema obliteration. With the attached skin island on the lowest portion of the rectus muscle, rotating the flap inferiorly into the long axis of the rectus muscle provided considerable added length. The added length has permitted flap transposition to the apex of the thorax, which was not possible in previous reports. ${ }^{4,9}$ The deepithelialized skin island has provided adequate soft tissue volume for complete dead space obliteration. The dead space requirements in these patients could not have been met by a single local muscle flap. The use of the skin island has been critical to and effective in 
managing the length and volume requirements in these reconstructions.

Secondary infection is an unfortunate and not infrequent complication of treating patients with postpneumonectomy empyemas. One of our patients did have a secondary infection after obliteration of the tract with the TRAM flap. In this instance, the TRAM flap had probably reduced the size of the prior tract such that this secondary tract could be treated successfully with a Clagett procedure. We would, therefore, recommend this secondary Clagett technique for the limited recurrent tract after our obliteration procedure. Although this was an unexpected complication, we had the opportunity to demonstrate that a small recurrence after the TRAM flap could be easily managed. Although we did not encounter a large recurrent tract in our series, we would consider a second obliteration procedure with the omentum or a free flap for this problem.

In summary, the deepithelialized unipedicle TRAM flap has provided successful long-term obliteration of the postpneumonectomy empyema tract when satisfactory local chest wall muscle was unavailable.

\section{REFERENCES}

1. Pairolero P, Arnold PG, Trastek VF, Meland NB, Kay PP. Postpneumonectomy empyema: the role of intrathoracic muscle transposition. J Thorac Cardiovasc Surg 1990;99:95868.
2. Dieter RA Jr, Pifarré R, Neville WE, Magno M, Jasuja M. Empyema treated with neomycin irrigation and closed chest drainage. J Thorac Cardiovasc Surg 1970;59:496-500.

3. Shamj FM, Ginsberg RT, Cooper JD, Spratt EH, Goldberg $M$, Waters $P F$, et al. Open window thoracostony in the management of postpneumonectomy empyema with or without bronchopleural fistula. J Thorac Cardiovasc Surg 1983; 86:818-22.

4. Miller JI, Mansour KA, Nahai F, Jurkiewicz MJ, Hatacher CR Jr. Single-stage complete muscle flap closure of the postpneumonectomy empyema space: a new method and possible solution to a disturbing complication. Ann Thorac Surg 1984;38:227-31.

5. Dorman JP, Campbell D, Grover FL Trinkle JK. Open thoracostomy drainage of postpneumonectomy empyema with bronchopleural fistula. J Thorac Cardiovasc Surg 1973; 66:979-81.

6. Asamura $H$, Goya T, Naruke T, Tsuchiya R, Kondo H, Suemasu $\mathrm{K}$, et al. Closure of fenestra in Clagett procedure: use of rectus abdominis myocutaneous flap. Ann Thorac Surg 1992;54:147-9.

7. Arnold P, Pairolero P. Intrathoracic muscle flaps. Ann Surg 1990;211:660-2.

8. Clagett OT, Geraci JE. A procedure for the management of postpneumonectomy empyema. J Thorac Cardiovasc Surg 1963;45:141-5.

9. Hallock GG. Intrathoracic application of the transverse rectus abdominis musculocutaneous flap. Ann Plast Surg 1992;29:357-61.

10. Hammond DC, Fisher J, Meland NB. Intrathoracic free flaps. Plast Reconstruct Surg 1993;91:1259-64.

11. Chen HC, Tang YB, Noordhoff MS, Chang CH. Microvascular free muscle fiaps for chronic empyema with bronchopleural fistula when the major local muscles have been divided-one stage operation with primary wound closure. Ann Plast Surg 1990;24:510-6. 